\title{
Sistema nacional, plano nacional e gestão democrática da educação no Brasil: articulações e tensões
}

\author{
National system, national plan and democratic management of Education in Brazil: \\ articulations and tensions
}

\section{Sistema nacional, plan nacional y gestión democratica de la educación en Brasil: articulaciones $y$ tensiones}

\author{
VERA MARIA VIDAL PERONI* \\ MARIA LUIZA RODRIGUES FLORES**
}

\begin{abstract}
RESUMO - O artigo aborda a democratização da educação, a partir do conteúdo do atual Plano Nacional de Educação (PNE), enfocando o histórico recente de elaboração destes Planos no Brasil. O estudo resgata o processo de tramitação do Projeto de Lei 8035/10 referente ao atual PNE até sua aprovação na Lei 13.005/14, evidenciando algumas contradições neste processo em relação aos objetivos e pressupostos da Conferência Nacional de Educação - CONAE 2010. É realizada uma comparação entre algumas propostas desta CONAE e o texto da nova Lei em relação aos temas gestão democrática e relação entre o público e o privado na oferta educacional. Por fim, são destacados alguns elementos acerca das possibilidades que este atual PNE traz para a efetivação do direito à educação no país, ressaltando que a nova Lei apresenta alguns avanços em vários temas, mas pode significar retrocessos quanto à democratização da educação, considerando-se as diferentes formas de privatização presentes na política educacional.
\end{abstract}

Palavras-chave - Política Educacional. Gestão Democrática. Plano Nacional de Educação. Sistema Nacional de Educação. Relação público/privado.

\begin{abstract}
The article discusses the democratization of education from two interrelated themes: the National Education Plan (NEP) and the proposal for the creation of a National Education System (NES), focusing on the recent history of the development of these plans in Brazil, as well as the process of creation of the NES. The study analyzes the process of discussion of Law 8035/10, which concerns to the new NEP, highlighting some contradictions of this process as towards goals and assumptions of the National Education Conference 2010 - CONAE. A comparison is made between the proposals of the CONAE and the text of the new Law on issues of concerning democratic management of education and the relationship between public and private in the educational provision. Finally, some points for discussion were presented on the role of the possibilities that the new Law contributes to the realization of the right to education in the country, stressing that the new law presents some progress on several issues, but it can mean setbacks and the democratization of education, considering the different forms of privatization present in educational policies.
\end{abstract}

Keywords - Educational Policy. Democratic Management. National Education Plan. National Education System. Public/private relationship.

RESUMEN - El artículo aborda la democratización de la educación, a partir del contenido del actual Plan Nacional de Educación (PNE), enfocando el reciente histórico de elaboración de estos Planes en Brasil. El estudio rescata el proceso de tramitación del Proyecto de Ley 8035/10 relativo al actual PNE hasta su aprobación en la Ley 13.005/14, evidenciando algunas contradicciones en este proceso en relación a los objetivos y presupuestos de la Conferencia Nacional de Educación - CONAE 2010. Es realizada una comparación entre algunas propuestas de esta CONAE y el texto de la nueva Ley sobre los temas de gestión democrática y la relación entre lo público y privado en la oferta educacional. Por último, pone en relieve algunos elementos de las posibilidades que el nuevo PNE aporta en la realización del derecho a la educación del país, haciendo hincapié que esta Ley actual presenta algunos avances en varios temas, pero que puede significar retrocesos como en la democratización de la educación, considerando las diferentes formas de privatización presentes en las políticas educativa.

Palabras clave - Política Educativa. Gestión Democrática. Plan Nacional de Educación. Sistema de Educación Nacional. Relación público/privada.

\footnotetext{
* Doutora em Educação pela Universidade Federal do Rio Grande do Sul (Porto Alegre, RS, Brasil) e Professora da Universidade Federal do Rio Grande do Sul (Porto Alegre, RS, Brasil).E-mail: <veraperoni@yahoo.com.br>.

** Doutora em Educação pela Universidade Federal do Rio Grande do Sul (Porto Alegre, RS, Brasil) e Professora da Universidade Federal do Rio Grande do Sul (Porto Alegre, RS, Brasil). E-mail:<m.rosimary@gmail.com.br>.
} 


\section{INTRODUÇÃO}

O objetivo principal deste artigo é incentivar o debate acerca do tema da democratização da educação, discutindo desde um contexto mais amplo qual é a proposta de gestão democrática que a sociedade brasileira quer construir e, especialmente, qual é o papel da educação neste processo. Trata-se de um tema que julgamos essencial neste momento histórico em que, a nosso ver, parecem restar ameaçadas algumas conquistas de espaços democráticos, ainda em processo inicial de consolidação no Brasil.

Dando materialidade a este objetivo, abordaremos dois temas inter-relacionados que consideramos importantes no contexto da democratização da educação: o Plano Nacional de Educação (PNE) e a importância da criação de um Sistema Nacional de Educação (SNE) em um país desigual como o Brasil. Desde nosso ponto de vista, a relação entre o público e o privado e a gestão democrática se constituem em pilares centrais para a garantia do direito à educação pública, gratuita, laica e de qualidade, firmada como direito social inalienável em nossa Constituição Federal de 1988 (CF/88) (BRASIL, 1988). No contexto atual da recente aprovação do novo PNE, Lei 13005/14 com o estabelecimento de metas e de estratégias para a efetivação de políticas educacionais para os próximos dez anos, os dois temas aqui tratados assumem especial relevância, havendo entre ambos uma delicada relação de interdependência.

Estruturamos o artigo buscando trabalhar estes temas em relação, contextualizando a situação do país no que tange aos Planos Nacionais de Educação na seção inicial, com análises sobre o PNE aprovado em 2001, através da Lei $n^{\circ}$ 10.172, de 09 de janeiro de 2001 (BRASIL, 2001), com prazo de vigência expirado em 2010. A seguir, apresentamos o processo de tramitação do Projeto de Lei (PL) no 8.035/2010 (BRASIL, 2011), referente ao novo PNE aprovado no Congresso Nacional e sancionado pela Presidente Dilma Roussef em junho de 2014, evidenciando algumas contradições deste processo em relação aos objetivos e pressupostos da última Conferência Nacional de Educação (Conae) 2010.

$\mathrm{Na}$ seção seguinte, iniciamos abordando o SNE, estrutura exigida em um modelo de sociedade tão desigual quanto a brasileira, para que possamos, de fato, falar em democracia, justiça e equidade na oferta educacional para todos. De forma relacionada, desenvolvemos os temas gestão democrática e a relação entre o público e o privado na oferta educacional, buscando evidenciar a interdependência entre ambos.

Por fim, apresentamos algumas considerações, retomando os objetivos do artigo, no intuito de evidenciar os descompassos nos trâmites da legislação e as divergências de conteúdo nos documentos trabalhados.
Nas conclusões, damos destaque ao momento políticoeconômico atual, pois se trata, a nosso ver, de um momento no qual os caminhos que se abrem são radicalmente diferentes em termos de impacto sobre a garantia do direito social fundamental à educação pública de qualidade social.

\section{A CONSTRUÇÃO dOS PLANOS NACIONAIS DE EDUCAÇÃ̃O NO BRASIL: OS CASOS DA LEI No 10.172/2001 E DA LEI 13.005/2014}

Iniciamos abordando o processo de elaboração do primeiro PNE brasileiro dos anos pós-CF/1988 (BRASIL, 1988), haja vista a importância daquele período histórico e o envolvimento da sociedade na trajetória de construção da gestão democrática em educação, sem desconsiderar que o Manifesto dos Pioneiros, em 1932, já fazia menção à necessidade de um documento com estes objetivos e que, em função da repercussão destas ideias e da pressão social, a Constituição Brasileira de 1934 (BRASIL, 1934) recebeu um artigo com referência a este instrumento.

Passados quase 10 anos da aprovação da $\mathrm{CF} / 88$ (BRASIL, 1988), a partir de intensa mobilização da sociedade civil organizada pelo Fórum Nacional em Defesa da Escola Pública (Fndep) ${ }^{1}$ foi elaborada uma proposta de PNE, construída a partir de dois Congressos Nacionais de Educação (Coned), um em 1996 e outro em 1997, em Belo Horizonte (FÓRUM, 1997). ${ }^{2}$

Esta proposta de PNE da sociedade civil, expressando os compromissos do Fndep, assumidos desde a Assembleia Nacional Constituinte (ANC), foi apresentada ao Congresso Nacional, através do Deputado Ivan Valente, como Projeto de Lei (PL) no 4.155/1998 (BRASIL, 1998). Porém, o Poder Executivo enviou mensagem do Ministério de Educação ao Congresso Nacional, que resultou na tramitação do PL no 4.173/1998 (BRASIL, 1998), apensado ao primeiro, o qual, finalmente, aprovado em 2001, sob a forma da Lei $n^{\circ}$ 10.172/2001 (BRASIL, 2001), estabeleceu diretrizes e metas para a educação brasileira referentes ao decênio 2001-2010.

A despeito da intensa mobilização da sociedade civil e, especialmente do Fndep durante toda a tramitação, este PNE expressou parcialmente os anseios e propostas da sociedade da época, embalada por ideais democráticos. Prejudicou a realização das metas e dos objetivos estabelecidos para as diferentes etapas e modalidades educacionais, o veto presidencial relativo às fontes de financiamento previstas no Item 11.3, subitem 1, cujo texto original previa a elevação anual do percentual de gastos públicos na área à razão de $0,5 \%$ do Produto Interno Bruto (PIB), de forma a atingir até o final da década da educação, um mínimo de 7\%. 
Com prazo expirado em 2010, este PNE deixou a desejar em diferentes aspectos, tomando-se o princípio constitucional da gestão democrática em educação e a necessidade de uma coordenação nacional de ações para a efetivação de suas metas: a articulação e a produção da sociedade civil consolidadas na proposta do Fndep foram desconsideradas, e não se efetivou a necessária destinação de recursos que favorecessem a consecução dos objetivos, nem mesmo daqueles constantes do texto aprovado pelo Congresso Nacional. As indicações presentes no próprio texto da Lei $\mathrm{n}^{\mathrm{o}}$ 10.172/2001 (BRASIL, 2001) quanto ao papel do Governo Federal de promover avaliação periódica do alcance de suas metas jamais foram cumpridas, minimizando o compromisso do Estado e inviabilizando o controle social da política e do gasto públicos.

$\mathrm{Na}$ mesma linha de omissão do Estado, as ações necessárias no sentido de exigir dos gestores estaduais e municipais a elaboração dos seus planos de educação à luz do PNE e mesmo aquelas necessárias para apoiá-los nesta tarefa não foram realizadas. Sem os respectivos planos das unidades da federação e dos municípios, a população ficou sem ferramentas para pressionar em nível local pela destinação de recursos nos planos plurianuais para a realização das metas que deveriam ter sido assumidas pelos gestores públicos durante seus governos.

Quando foi iniciado o processo de organização das conferências de educação preparatórias à Conae 2010, uma das ausências sentidas pela sociedade foi a apresentação pelo Governo Federal de um diagnóstico relativo ao alcance das metas do PNE 2001-2010, desencadeando-se o processo de elaboração de um novo PNE sem base de dados para a avaliação do anterior e para projeção das ações para o próximo decênio. Podemos somar a essa, a ausência de uma nota técnica do Ministério da Educação (MEC), relativa aos investimentos necessários à execução das metas propostas, o que só veio a acontecer após a pressão da sociedade civil organizada e, ainda assim, com critérios e valores que deixaram margem para questionamentos.

Quanto à tramitação do PL no 8.035/2010 (BRASIL, 2011), a partir de 2008, o Governo Federal promoveu um processo de mobilização da sociedade com a realização de conferências descentralizadas nos municípios e estados brasileiros, realizando a discussão e votação de um Documento-Referência elaborado pela Comissão Organizadora da Conae. Esta Comissão, de composição mista, possuía representantes da sociedade civil e da sociedade política e o Documento foi apresentado como parâmetro inicial estruturante do texto do novo PNE.

Durante o ano de 2009, foram realizadas conferências municipais, regionais e estaduais, com financiamento público e participação ampla da sociedade civil, de agentes públicos e de todos os segmentos da comunidade escolar, com o objetivo de discutir aquele Documento e a ele acrescentar temas ou questões. Em cada comunidade escolar e rede de ensino pública ou privada houve intensa mobilização, de forma que a sociedade manifestou seu interesse em participar deste processo, culminado com a realização da Conae entre Março e Abril de 2010, em Brasília, com a presença de quase 4000 pessoas, entre delegados, organizadores, imprensa e demais participantes de todo o país, representando diferentes segmentos e entidades.

O trabalho dos delegados se efetivou na expectativa de contribuir com voz e voto para a elaboração do Documento Final da Conferência, que seria entregue ao MEC para constituir-se na base do PL referente ao novo PNE. Em consequência das conferências de 2009, muitas propostas chegaram às mãos da Comissão de Sistematização, sendo várias incorporadas ao Documento original. Como regra para os acréscimos de emendas ou propostas ao texto original, a nova matéria deveria ter sido formulada e encaminhada por mais de cinco estados brasileiros, evidenciando assim sua representatividade.

Conforme consta no Documento-Base apresentado aos delegados da Conae 2010, "Foram inseridas pelas comissões estaduais e do Distrito Federal, no Sistema de Relatoria, 5.300 propostas, entre emendas aos parágrafos ou novos parágrafos, resultando em um documento de 2.600 páginas." (BRASIL.MEC, 2010b, p. 7). Após o término da Conae, seu Documento Final (BRASIL. MEC.SE, 2010a) foi sistematizado pela Comissão Organizadora Nacional e entregue ao Ministro da Educação, Fernando Haddad. De parte da sociedade civil, ficou a expectativa de que em breve e de maneira consolidada, as deliberações da Conferência, aprovadas nas plenárias por seus delegados, passariam a compor o texto do PL a ser encaminhado ao Congresso Nacional, consolidando o processo democrático de votação.

Entre a entrega do Documento Final ao MEC e o encaminhamento do PL no 8.035/2010 (BRASIL, 2011) pelo Ministro da Educação Fernando Haddad à Câmara Federal, em 15 de dezembro de 2010, passaram-se oito meses. A tramitação deste PL na Comissão Especial da Comissão de Educação da Câmara, ao longo dos anos de 2011 e 2012 gerou intensa mobilização da sociedade, sendo ameaçado por sucessivos anúncios de enxugamento de prazos e redução de instâncias de participação democrática. Entre anúncios de divulgação do Relatório e vários cancelamentos de sua apresentação pelo Deputado Ângelo Vanhoni - Partido dos Trabalhadores/Paraná (PT/PR) -, relator da Comissão de Especial do PNE da Comissão de Educação da Câmara dos Deputados, os movimentos sociais se esforçaram para entender o que estava acontecendo, sem perder de vista a urgência da pressão cotidiana no Congresso. 
As análises realizadas por diferentes entidades da sociedade civil $^{3}$ sobre a versão do PL 8035/10 apresentada pelo Relator Angelo Vanhoni em 06 de dezembro de 2011 evidenciam que o texto deixou muito a desejar, frustrando a sociedade brasileira com a apresentação de metas tímidas e estratégias pouco propositivas para os níveis, etapas e modalidades educacionais, desconsiderando parte substancial das recomendações presentes no Documento final da Conae (BRASIL. MEC.SE, 2010a).

Mobilizada por entidades como a Campanha Nacional pelo Direito à Educação, a União Nacional dos Dirigentes Municipais de Educação (Undime), a Confederação Nacional dos Trabalhadores em Educação (CNTE) e a União Nacional dos Estudantes (UNE), para citar apenas algumas, a sociedade civil se organizou garantindo sua contribuição através de mais de 2.900 emendas parlamentares ao Relatório, ${ }^{4}$ evidenciando o apoio de vários parlamentares às sugestões apresentadas.

As emendas foram sistematizadas pela Undime, em trabalho de apoio à Comissão Especial do PNE e, após a apresentação de uma segunda versão, novo período de apresentação de emendas foi aberto, gerando, ao longo do período de tramitação, mais de uma rodada de apresentação de emendas ao Relatório da Comissão. Neste movimento, intensa campanha foi realizada em prol da defesa da destinação de $10 \%$ do PIB para a educação. Após a experiência do PNE 2001-2010 (BRASIL (2001), cuja previsão de recursos foi vetada, a consciência sobre a necessidade de destinação clara de recursos e, sobretudo, de um maior aporte e de novos recursos, se tornou bandeira nacional e tomou as ruas do país em passeatas, eventos e panfletos, mobilizando fortemente as redes sociais. ${ }^{5}$

Finalmente, em 16 de outubro de 2012, o PL n 8.035/2010 (BRASIL, 2011) foi aprovado pela Comissão de Constituição e Justiça da Câmara dos Deputados com a aprovação de $10 \%$ do PIB para a educação, além da destinação de $50 \%$ dos royalties da camada pré-sal do petróleo para investimento em educação, a despeito dos anúncios do governo de que não haveria recursos suficientes para garantir aquele índice (BRASIL.CD, 2012). As questões referentes ao necessário compromisso do poder público com o financiamento da educação repercutiram no atraso de votação do PL, pois ao mesmo tempo em que os parlamentares pressionados pela sociedade reconheciam a necessidade de mais recursos, eram, também, pressionados pelo Governo Federal com argumentos sobre a impossibilidade de implementação uma proposta de financiamento mais arrojada para os próximos dez anos, inclusive devido à crise internacional que vive o sistema financeiro com reflexos na economia nacional.

Apesar da aprovação dos $10 \%$ do PIB, o texto aprovado na Câmara Federal ainda se encontrava longe das propostas do Documento Final da Conae em termos de comprometimento do poder público com o financiamento de uma educação de qualidade social para todos, consolidada a partir da efetivação de um Sistema Nacional Articulado de Educação e com a garantia de investimentos adequados a uma oferta educacional pública com qualidade. Afirmamos isso, pois aquele Documento apresentou a proposta de que os investimentos em manutenção e desenvolvimento do ensino incluíssem $100 \%$ dos royalties, participações especiais e bônus dos hidrocarbonetos e demais minerais e $50 \%$ do Fundo Social do Pré-sal.

A análise do contexto atual de crise do capital, de diminuição do crescimento do PIB brasileiro, assim como dos próprios recursos que compõem o Fundo de Manutenção e Desenvolvimento da Educação Básica e de Valorização dos Profissionais da Educação (Fundeb) aponta para um cenário no qual os recursos destinados diretamente à educação pública brasileira não estão claramente definidos, pois a destinação dos novos recursos necessários para uma oferta educacional maior e de melhor qualidade está atrelada a um contexto mais amplo, e dependente do panorama mundial. O investimento dos futuros royalties oriundos da exploração da camada présal do petróleo em educação tornou-se uma possibilidade, ainda que análises econômicas e políticas apontem tal condição como distante em função do tempo necessário para sua efetivação.

Após 18 meses de tramitação na Câmara, o Governo Federal tentou, através do Recurso 162/2012, atrasar o envio do Projeto do novo PNE ao Senado Federal, mas esse Recurso foi derrubado. ${ }^{6}$ Durante a tramitação no Senado Federal, a mobilização social se manteve, mas o PL 8035/10 recebeu uma alteração determinante na Meta 20: trata-se da retirada da expressão "pública", que do ponto de vista prático, abriu a brecha para que também fosse considerado como um tipo de investimento em educação pública, aqueles gastos realizados com uma educação não integralmente assumida pelo Estado.

Entre 2012 e 2014, o PL no 8.035/2010 (BRASIL, 2011) tramitou no Senado e retornou à Câmara dos Deputados, onde a expressão "pública" retornou à Meta 20, que reassumiu sua redação original. Contudo, a Lei que aprova o novo PNE teve seu texto acrescido na Comissão Especial da Câmara, de forma a permitir um complexo "alargamento" do entendimento daquilo que passou a significar investimento público em educação, passando a contemplar incentivos, bolsas de estudo e isenções fiscais. Finalmente, aprovado em 03 de junho de 2014, o texto seguiu para sanção presidencial, sendo sancionada sem vetos pela Presidente Dilma Roussef, em 25 de junho deste ano, a Lei 13.005/14 que aprova o PNE para o próximo decênio. 
Na próxima seção, analisaremos como se apresentam as redações finais de duas das metas do novo PNE que dialogam com o tema gestão da educação, relacionando estas análises à necessária criação de um SNE, como articulação indispensável aos avanços demandados face à realidade educacional brasileira.

\section{Sistema NACIONAL dE EdUCAÇÃo E GESTÃO DEMOCRÁTICA}

A construção de um Sistema Nacional de Educação foi proposta pelo Fndep em um momento de abertura política e de luta pela construção de uma sociedade democrática, ainda que já se configurasse àquela época, principalmente nos países centrais, um modelo de retirada do Estado da efetivação de direitos sociais. A correlação de forças no Brasil daquele período era muito diferente da atual, e os setores que defendiam a escola pública e a democratização construíram uma proposta a partir destes objetivos, na esteira do processo de redemocratização em curso. Apresentamos a seguir o texto original da Proposta de Sistema Nacional de Educação construído no Fndep e materializada no texto do PNE da Sociedade Civil:

[...] defende-se a instituição de um Sistema Nacional de Educação para o Brasil, concebido como expressão institucional do esforço organizado, autônomo e permanente do Estado e da sociedade brasileira pela educação, tendo como finalidade precípua a garantia de um padrão unitário de qualidade nas instituições educacionais públicas e privadas em todo o país. [...] As ações do Sistema Nacional de Educação, eixo central da organização da educação nacional, devem simplificar as estruturas burocráticas, descentralizar os processos de decisão e execução, fortalecer as escolas e as unidades prestadoras de serviços, articular os diferentes níveis e sistemas de ensino, integrar a educação formal e a informal, articular a educação escolar com as ações educativas produzidas no interior dos movimentos populares, valorizar os processos de avaliação institucional. (FÓRUM, 1997, p. 31).

A proposta do Fndep vinculava o Sistema Nacional de Educação a um Fórum representativo da sociedade civil que fosse capaz de construir políticas de Estado e não apenas de governo, como podemos ver no trecho a seguir:

Sistema Nacional de Educação, assim configurado, tem como instância máxima de deliberação o Fórum Nacional de Educação, com ampla representação dos setores sociais envolvidos com a educação, responsável pela política nacional de educação e, principalmente, pela definição de diretrizes e prioridades dos planos nacionais de educação e sobre a execução orçamentária para a área. (FÓRUM, 1997, p. 29) (grifo das autoras).
A despeito de que, no PNE 2001-2010 (BRASIL, 2001), tal proposição não se consolidou, é importante ressaltar que a mesma foi incorporada à CF 1988 (BRASIL, 1988) pela Emenda Constitucional (EC) no 59, de 11 de novembro de 2009 (BRASIL, 2009) que, deu nova redação ao artigo no 214 da Carta Magna, enfatizando o papel articulador do PNE em relação ao SNE. Destacamos, ainda, deste documento legal, a ênfase dada ao regime de colaboração entre os entes federados, assim como ao necessário estabelecimento de metas para aplicação de recursos públicos na educação, em função das desigualdades existentes em nosso país:
Art. 4ํ O caput do art. 214 da Constituição Federal passa a vigorar com a seguinte redação, acrescido do inciso VI: art. 214. A lei estabelecerá o plano nacional de educação, de duração decenal, com o objetivo de articular o sistema nacional de educação em regime de colaboração e definir diretrizes, objetivos, metas e estratégias de implementação para assegurar a manutenção e desenvolvimento do ensino em seus diversos níveis, etapas e modalidades por meio de ações integradas dos poderes públicos das diferentes esferas federativas que conduzam a: [...] VI - estabelecimento de meta de aplicação de recursos públicos em educação como proporção do produto interno bruto. (NR) (BRASIL, 2009).

A Conae 2010 também reforçou esta ideia através de seu tema central: "Construindo o Sistema Nacional Articulado de Educação: o Plano Nacional de Educação, Diretrizes e Estratégias de Ação", evidenciando o papel de destaque dado à construção de um SNE necessariamente articulado, como ferramenta estratégica de realização de seus objetivos. Na Introdução do Documento-Base da Conae 2010, são depositadas no processo participativo de construção do novo PNE, expectativas em relação à execução de políticas de Estado para a garantia da qualidade da educação:

A Conferência Nacional de Educação (CONAE) a ser realizada em 2010, precedida por conferências municipais e estaduais em 2009, será um acontecimento ímpar na história das políticas públicas do setor educacional no Brasil. [...]. Essa dinâmica políticopedagógica será valioso contributo à discussão dos programas e ações governamentais, a fim de consolidar a educação como direito social, a democratização da gestão, o acesso e a garantia da permanência bem sucedida de crianças, adolescentes, jovens e adultos nas instituições de ensino brasileiras e o respeito e a valorização à diversidade. E, sobretudo, por ensejar, enfim, a construção de uma política de Estado, na área da educação, para o Brasil. (BRASIL, 2010b, p. 11-12).

Entendemos que, garantir o direito à educação é uma obrigação do Estado e, como tal, demanda políticas 
públicas. Definições acerca das relações entre o setor público e o privado, e entre os entes federados, incluindo o papel da União no financiamento e na regulação da Educação Básica constituem-se alguns dos principais desafios para a construção do SNE.

Ao longo de nossa história, a União esteve praticamente ausente em termos de apoio técnico e financeiro à Educação Básica, conforme demonstra Castro (2010), a partir do conceito de Gasto Público Educacional, evidenciando que na série histórica 19952007 houve pequeno comprometimento do Governo Federal com o investimento necessário à expansão deste nível.

A desobrigação histórica da União com a oferta da educação básica reforçou desigualdades regionais tanto na cobertura, quanto na qualidade da oferta, pois estados e municípios com maior poder de investimento tiveram mais condições de investir em educação, a despeito dos fundos criados para a redistribuição de recursos para a educação pública ${ }^{7}$ cuja expectativa de suplementação da União, praticamente não aconteceu, apesar de ser este o ente federado que fica com a maior fatia dos recursos arrecadados no País através de taxas e impostos.

Equalizar as condições de acesso à educação pública de qualidade é, sem dúvida, um desafio enorme, pois totalmente novo na nossa história, configurando-se em um processo que necessita ser construído coletivamente e com participação efetiva nos processos decisórios, para evitarmos o risco de centralizar e desrespeitar o pacto federativo. Como existem projetos educativos em disputa, assumirão significativa importância os interlocutores do Estado e da sociedade civil organizada que estiverem na coordenação da elaboração das políticas educacionais para os próximos dez anos de vigência do novo PNE.

A composição do Fórum Nacional de Educação (FNE), instituído pela Portaria $n^{\circ} 1.407$, de 14 de dezembro de 2010 (BRASIL, MEC, 2010), passa a ter importância fundamental, já que a correlação de forças no momento atual é diferente daquele em que tal Fórum foi pensado, ainda durante o período de redemocratização do país. Para a construção de um SNE é importante saber quem são os interlocutores do Governo Federal, qual será o espaço dos diferentes sujeitos na construção da política e qual é o papel, a composição e a correlação de forças presente no Fórum Nacional de Educação (FERNANDES; BRITO; PERONI, 2012).

Tomando-se como referência o contexto sociopolítico e econômico atual, a instituição de um SNE articulado pode significar uma contraposição à tendência neoliberal, de retirada do poder público da execução de políticas sociais, indicando uma maior presença do Estado na coordenação das políticas educacionais e garantindo maior democratização da educação. Contudo, a correlação de forças vigente aponta para uma maior presença do setor privado mercantil influenciando, inclusive, a direção da política educacional, em um momento em que setores empresariais organizados têm materializado esta influência de diversas formas, ${ }^{8}$ a despeito das deliberações da Conae 2010 sobre as relações entre o público e o privado:

As instituições do setor privado, por fazerem parte do Sistema Nacional de Educação, subordinam-se ao conjunto de normas gerais de educação e devem se harmonizar com as políticas públicas, que têm como eixo o direito à educação, e acatar a autorização e avaliação desenvolvidas pelo poder público. Dessa forma, no que diz respeito ao setor privado, o Estado deve normatizar, controlar e fiscalizar todas as instituições, sob os mesmos parâmetros e exigências aplicados às do setor público. (BRASIL.MEC.SE, 2010b, p. 32) (grifo das autoras).

Ignorando esta posição da Conae 2010, a aplicação de significativa parcela de recursos federais destinados ao financiamento da educação não esperou pela aprovação do novo PNE. Políticas de governo vêm sendo implementadas neste ínterim, utilizando recursos públicos na efetivação de programas e projetos muitas vezes orientados por concepções diametralmente opostas aquelas presentes no Documento Final da Conae 2010 (BRASIL.MEC.SE, 2010a). ${ }^{9}$

A iniciativa privada, nomeada como parceira para a realização de programas e projetos desde a primeira etapa da educação básica até a educação superior, incluindo modalidades como a educação de jovens e adultos, a educação profissional e a educação especial tem sido privilegiada com a destinação de recursos públicos, de diferentes formas. ${ }^{10}$ Essa opção do Governo Federal, por si só, aponta uma tendência privatista da educação, que fragiliza, em nosso entendimento, os próprios princípios constitucionais de gratuidade, laicidade e qualidade, comprometendo, ainda, o compromisso com a gestão democrática na educação pública.

A democracia aqui é entendida como a materialização de direitos e igualdade social, e a não separação entre o econômico e o político (PERONI, 2006); ${ }^{11}$ está vinculada ao direito à educação materializado em políticas e também ao processo de construção destas políticas, pois conforme Vieira (2001), a democracia envolve coletivização das decisões e a participação é um processo de aprendizagem, que ocorre na prática. Conforme Mészáros, “[...] programas e instrumentos de ação sociopolíticos verdadeiramente adequados só podem ser elaborados pela própria prática social crítica e autocrítica no curso de seu desenvolvimento" (MÉSZÁROS, 2002, p. 1.008). 
Entendemos que a gestão democrática na educação é parte do projeto de construção da democratização da sociedade brasileira e não simplesmente uma mudança na forma de gestão, que passaria da tecnocrática, vinculada aos preceitos do Fordismo ou atualmente do Toyotismo, para a democrática. (PERONI, 2010). A construção do projeto político-pedagógico, a participação em conselhos de escola, a eleição para diretores, o exercício da autonomia financeira, são processos pedagógicos de aprendizagem da democracia, tanto para a comunidade escolar, quanto para a comunidade em geral, porque a participação exige um longo processo de construção no qual a gestão democrática é um fim, mas também um meio.

O entendimento de que a educação tem um papel importante na construção de uma cultura democrática e de que o direito a esta aprendizagem deveria ser vivenciada por todos os sujeitos da comunidade escolar de escolas públicas e privadas foi argumento vencido no período Constituinte, prevalecendo na CF/88 (BRASIL, 1988) o preceito da gestão democrática apenas para as escolas públicas. Este tema, por sua relevância foi retomado na Conae 2010, ficando registrado em seu texto final:

[...] democratizar a gestão da educação e das instituições educativas (públicas e privadas), garantindo a participação de estudantes, profissionais da educação, pais/mães e/ou responsáveis e comunidade local na definição e realização das políticas educacionais, de modo a estabelecer o pleno funcionamento dos conselhos e órgãos colegiados de deliberação coletiva da área educacional, por meio da ampliação da participação da sociedade civil; instituir mecanismos democráticos - inclusive eleição direta de diretores/as e reitores/as, para todas as instituições educativas (públicas e privadas) e para os sistemas de ensino; e, ainda, implantar formas colegiadas de gestão da escola, mediante lei específica. (BRASIL MEC.SE, 2010a, p. 44) (grifo das autoras).

Analisando o conteúdo do novo PNE em relação à gestão democrática, observamos que não foi incorporada a deliberação da Conae 2010 acima trazida, constando o seguinte texto como diretriz do PNE na Lei 13.005/14, Art. 2을 Inciso VI: “- Promoção do princípio da gestão democrática da educação pública" (BRASIL, Lei 13.005, Art. 2º, Inciso VI, 2014).

Na Meta 19 do novo PNE, a proposta de gestão democrática aparece, dando lugar, em nosso entendimento, a um modelo de gestão gerencial, que aponta de forma genérica a participação da comunidade escolar, ao mesmo tempo em que apresenta princípios gerenciais como critérios técnicos de mérito e desempenho. Diz o texto desta Meta: "[...] assegurar condições, no prazo de 2 (dois) anos, para a efetivação da gestão democrática da educação, associada a critérios técnicos de mérito e desempenho e à consulta pública à comunidade escolar, no âmbito das escolas públicas, prevendo recursos e apoio técnico da União para tanto" (BRASIL, 2014, Meta 19).

Se por um lado, a consulta pública à comunidade escolar prevista na Meta 19 pode significar um avanço nos locais onde não há histórico de gestão democrática, seja na forma de lei própria, seja na forma da vivência de processos democráticos, por outro lado, cabe um alerta no sentido de que a associação de critérios técnicos de mérito e desempenho a essa consulta à comunidade restringe a própria efetividade deste princípio. Em nosso entendimento, esta redação tenta articular em um mesmo texto dois mecanismos de gestão que representam concepções diferentes e mesmo antagônicas de gestão, uma de matriz democrática e outra vinculada a modelos de viés gerencial, restando aos entes federados o desafio de implementar em conjunto critérios tão distintos. Cabe, ainda, destacar o fato de que a expressão "consulta pública" pode não significar exatamente a eleição direta de dirigentes escolares.

Verificamos, que a Meta 19 do novo PNE contraria o texto aprovado na Conae 2010, em processo democrático: "Lei própria deve garantir a eleição direta para diretores/as (gestores/as) das escolas federais, estaduais, distritais e municipais da educação [...]" (BRASIL.MEC. SE, 2010a, p. 44).

Além disso, a Estratégia 1 da Meta 19 atrela critérios técnicos e de desempenho ao repasse de recursos financeiros incluindo no PNE outra estratégia gerencialista, pois apesar de muitos artigos do Plano abordarem o regime de colaboração, os sistemas de ensino deverão obrigatoriamente adotar critérios técnicos de desempenho que vão de encontro a concepções e práticas de gestão democrática, para receber os recursos públicos a que têm já direito. Diz o texto:

[...] 19.1) priorizar o repasse de transferências voluntárias da União na área da educação para os entes federados que tenham aprovado legislação específica que regulamente a matéria na área de sua abrangência, respeitando-se a legislação nacional, e que considere, conjuntamente, para a nomeação dos diretores e diretoras de escola, critérios técnicos de mérito e desempenho, bem como a participação da comunidade escolar; (BRASIL, 2014, Estratégia 19.1) (grifo das autoras).

Outro tema que cabe trazer à análise neste texto que trata da democratização da educação no contexto do atual PNE se refere ao financiamento da educação, do qual destacamos o parágrafo $4^{\mathrm{O}}$ do Artigo $5^{\mathrm{O}}$ e o texto aprovado na Meta 20 que tratam da ampliação de recursos públicos para a educação, da implantação do Custo AlunoQualidade inicial - CAQi, da implementação do Custo 
Aluno Qualidade - CAQ e da incorporação de instituições privadas no investimento público em educação. $\mathrm{O}$ texto da Meta 20 foi aprovado de forma a efetivar a demanda feita pela sociedade durante os quatro anos de tramitação do PNE, prevendo uma ampliação de recursos a partir do aumento do percentual de investimento em educação. Daquele total de $7 \%$ do PIB a ser alcançado até o final da década, como constou na primeira versão do Projeto, o texto aprovado avança com a seguinte redação:

[...] ampliar o investimento público em educação pública de forma a atingir, no mínimo, o patamar de $7 \%$ (sete por cento) do Produto Interno Bruto - PIB do País no 5o (quinto) ano de vigência desta Lei e, no mínimo, o equivalente a $10 \%$ (dez por cento) do PIB ao final do decênio. (BRASIL, PNE, Meta 20, 2014).

O patamar de $7 \%$ do PIB passa a ser meta intermediária, que deve ser alcançado no prazo de 5 anos da vigência do Plano. Além desta conquista, a Lei inclui redação de forma a garantir a ampliação dos recursos a serem aplicados em educação, também reconhecendo a demanda da sociedade que defendia a necessidade de "novos" recursos de forma a que o investimento maior em termos de PIB, tivesse novas fontes de financiamento:

$\S 5^{\circ}$ Será destinada à manutenção e ao desenvolvimento do ensino, em acréscimo aos recursos vinculados nos termos do art. 212 da Constituição Federal, além de outros recursos previstos em lei, a parcela da participação no resultado ou da compensação financeira pela exploração de petróleo e de gás natural, na forma de lei específica, com a finalidade de assegurar o cumprimento da meta prevista no inciso VI do art. 214 da Constituição Federal. (BRASIL, PNE, Artigo 5으, § 4º, 2014).

As estratégias 20.6; 20.7 e 20.10 também apontam para um avanço no que se refere ao alcance de um patamar mínimo de qualidade para a educação nacional, pois, se efetivadas, darão suporte para que o país se aproxime de padrões mínimos propostos pelo estudos que pelos estudos acerca do Custo Aluno Qualidade - CAQ. No conjunto do texto destas três estratégias, respectivamente, encontramse previstos: a implantação do Custo Aluno Qualidade inicial - CAQi no prazo de 2 (dois) anos da vigência do PNE com reajustes progressivos; a implementação do Custo Aluno Qualidade - CAQ [...] como parâmetro para o financiamento da educação de todas etapas e modalidades da educação básica [...]"; e, ainda, “[...] a complementação de recursos financeiros a todos os Estados, ao Distrito Federal e aos Municípios que não conseguirem atingir o valor do CAQi e, posteriormente, do CAQ." (BRASIL, PNE, Meta 20, Estratégias 20.6; 20.7 e 20.10, 2014).
Contudo, como já referimos anteriormente, o texto aprovado na Lei 13.005/14 alarga o conceito de "investimento público em educação pública", quando no $\S 4^{\circ}$ do mesmo Artigo $5^{\circ}$ ficou assim determinada a compreensão do que passa a ser considerado investimento público em educação:

O investimento público em educação a que se referem o inciso VI do art. 214 da Constituição Federal e a meta 20 do Anexo desta Lei engloba os recursos aplicados na forma do art. 212 da Constituição Federal e do art. 60 do Ato das Disposições Constitucionais Transitórias, bem como os recursos aplicados nos programas de expansão da educação profissional e superior, inclusive na forma de incentivo e isenção fiscal, as bolsas de estudos concedidas no Brasil e no exterior, os subsídios concedidos em programas de financiamento estudantil e o financiamento de creches, pré-escolas e de educação especial na forma do art. 213 da Constituição Federal. (BRASIL, PNE,

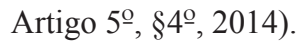

Dada à correlação de forças vigente, temos uma evidente tensão entre os princípios de compromisso do Estado com a oferta educacional pública de qualidade como garantia de direitos sociais fundamentais nas diferentes etapas, níveis e modalidades educacionais e, por outro lado, práticas de implementação de estratégias de privatização da definição e da execução da política pública na área educacional. Na seção seguinte, retomando os objetivos deste artigo e dentro do âmbito que foi possível desenvolver no escopo deste trabalho, apontamos algumas reflexões que se fazem necessárias acerca dos rumos da democratização da educação brasileira.

\section{Algumas CONSIDERAÇões}

Considerando-se os aspectos analisados neste artigo, podemos afirmar que, a par dos resultados positivos do intenso processo de mobilização da sociedade, dentro do período aqui analisado, em prol da aprovação de um novo PNE, entendemos que houve avanços e perdas para a consolidação de processos democráticos na educação brasileira com o texto final da Lei que aprova este Plano para o próximo decênio.

Sabemos, ainda, que este PNE era aguardado no âmbito dos estados e municípios da federação para que dele se desdobrassem os futuros planos estaduais, distrital e municipais de educação daqueles entes prioritariamente responsáveis pela oferta da Educação Básica no país. Nesse sentido, fica ainda a expectativa no processo de construção de um Sistema Nacional de Educação, que articule políticas educacionais de democratização do acesso e do conhecimento escolar em nível nacional sustentando os avanços necessários na área da educação. 
Realizamos neste artigo uma análise em relação aos processos de tramitação e efetivação dos Planos Nacionais de Educação, evidenciando algumas marcas que nos permitem questionar até que ponto estamos, de fato, vivendo a concretização do princípio constitucional da gestão democrática. Nossa intenção foi identificar aspectos tanto da forma de elaboração quanto do conteúdo proposto na Lei que cria o novo PNE, de maneira a evidenciar sinais de contradição ou mesmo de negação daquilo que vinha sendo construído no Brasil em termos de gestão educacional democrática, a partir do final da ditadura militar.

A partir das análises trazidas, defendemos a continuidade das ações de incidência política da sociedade, uma vez que novos embates deverão ocorrer no processo de implementação da Lei 13.005/14 e, ainda, durante a elaboração dos planos de educação próprios aos demais entes federados. Defendemos a necessidade de uma maior organização das entidades da sociedade civil, no sentido de que sejam realizados diagnósticos educacionais por todos os entes federados. Este diagnóstico local tem o objetivo de subsidiar a construção dos novos planos de educação para que os mesmos venham a significar avanços reais nas políticas educacionais nos próximos dez anos, a partir do estabelecimento de parâmetros para os futuros dirigentes estaduais e municipais de educação.

Ressaltamos, ainda, que a democracia é pedagógica em seu processo mesmo de efetivação, sendo o ambiente da escola um espaço privilegiado para esta construção. Entendemos que a naturalização da perda de avanços já havidos no campo da gestão democrática prejudica não apenas a efetivação da gestão democrática nas escolas, mas, também, coloca em risco a construção de um projeto de país mais democrático em todos os sentidos, já que a democracia não passa a existir apenas pela ausência ditadura.

Desejamos firmemente que a sociedade brasileira possa intervir nos processos de construção do Sistema Nacional de Educação e implementação do novo PNE, bem como dos respectivos planos de educação nos contextos locais, por serem todos estes instrumentos indispensáveis para o balizamento das políticas de governo. É preciso forte mobilização da sociedade para um efetivo avanço na educação, tanto em termos de gestão democrática, quanto de equidade no acesso, permanência e conclusão dos estudos nas suas diferentes etapas e modalidades.

\section{REFERÊNCIAS}

ASSOCIAÇÃO NACIONAL DE PÓS-GRADUAÇÃO E PESQUISA EM EDUCAÇÃO. Documento: por um Plano Nacional de Educação (2011-2020) como política de Estado. Rio de Janeiro: Armazém das Letras, 2011.

BOLLMANN, 2010. Revendo o Plano Nacional de Educação: proposta da sociedade brasileira. Educação \& Sociedade, Campinas, v. 31, n. 112, p. 657-676, jul.-set. 2010.
BRASIL. Câmara dos Deputados. Substitutivo ao Projeto de Lei no 8.035/2010, de junho de 2012. Aprova o Plano Nacional de Educação e dá outras providências. Brasília, 2012.

BRASIL. Constituição [de 1934] da República dos Estados Unidos do Brasil. Diário Oficial da União [da] República Federativa do Brasil. Rio de Janeiro, 16 jul. 1934.

BRASIL. Constituição [de 1988] da República Federativa do Brasil. Diário Oficial da União [da] República Federativa do Brasil, Brasília, 5 out. 1988.

BRASIL. Emenda Constitucional no 59, de 11 de novembro de 2009. Acrescenta $\S 3^{\circ}$ ao art. 76 do Ato das Disposições Constitucionais Transitórias para reduzir, anualmente, a partir do exercício de 2009, o percentual da Desvinculação das Receitas da União incidente sobre os recursos destinados à manutenção e desenvolvimento do ensino de que trata o art. 212 da Constituição Federal, dá nova redação aos incisos I e VII do art. 208, de forma a prever a obrigatoriedade do ensino de quatro a dezessete anos e ampliar a abrangência dos programas suplementares para todas as etapas da educação básica, e dá nova redação ao $\S 4^{\circ}$ do art. 211 e ao $\S 3^{\circ}$ do art. 212 e ao caput do art. 214, com a inserção neste dispositivo de inciso VI. Diário Oficial da União [da] República Federativa do Brasil, Brasília, 12 nov. 2009.

BRASIL. Lei no 10.172, de 09 de janeiro de 2001. Aprova o Plano Nacional de Educação (PNE). Diário Oficial da União [da] República Federativa do Brasil, Brasília, 10 jan. 2001.

BRASIL. Lei no 11.494 , de 20 de junho de 2007. Regulamenta o Fundo de Manutenção e Desenvolvimento da Educação Básica e de Valorização dos Profissionais da Educação - FUNDEB, de que trata o art. 60 do Ato das Disposições Constitucionais Transitórias; altera a Lei no 10.195 , de 14 de fevereiro de 2001; revoga dispositivos das Leis nos 9.424, de 24 de dezembro de 1996, 10.880, de 9 de junho de 2004, e 10.845, de 5 de março de 2004; e dá outras providências. Diário Oficial da União [da] República Federativa do Brasil. Brasília. 21 jun. 2007.

BRASIL. Lei no 9.394, de 20 de dezembro de 1996. Estabelece as Diretrizes e Bases da Educação Nacional. Diário Oficial da União [da] República Federativa do Brasil, Brasília, 23 dez. 1996a. BRASIL. Lei no 9.424, de 24 de dezembro de 1996. Dispõe sobre o Fundo de Manutenção e Desenvolvimento do Ensino Fundamental e de Valorização do Magistério, na forma prevista no art. $60, \S 7^{\circ}$, do Ato das Disposições Constitucionais Transitórias e dá outras providências. Diário Oficial da União [da] República Federativa do Brasil, Brasília, 26 dez. 1996b.

BRASIL. Lei $\mathrm{n}^{\mathrm{o}}$ 13.005, de 25 de junho de 2014. Aprova o Plano Nacional de Educação (PNE) e dá outras providências. Diário Oficial da União [da] República Federativa do Brasil, Brasília, 26 jun. 2014.

BRASIL. Ministério da Educação. Portaria Ministerial no 1.407, de 14 de dezembro de 2010. Brasília: MEC, 2010.

BRASIL. Ministério da Educação. Secretaria Executiva. Conferência Nacional de Educação 2010 - Construindo o sistema nacional articulado de educação: o plano nacional de educação, diretrizes e estratégias de ação. Documento Final. Brasília: MEC, 2010a.

BRASIL. Ministério da Educação. Secretaria Executiva. Documento-Base da Conferência Nacional de Educação (CONAE 2010). Brasília: MEC, v. 1, 2010 b.

BRASIL. Projeto de Lei do Plano Nacional de Educação (PNE 2011-2020): Projeto em tramitação no Congresso 
Nacional - PL no 8.035/2010. Brasília: Câmara dos Deputados, Edições Câmara, 2011 (Série Ação Parlamentar, 436).

BRASIL. Projeto de Lei no 4.155. Aprova o Plano Nacional de Educação. Diário da Câmara dos Deputados, Brasília, v. 53, n. 42, 12 mar. 1998.

BRASIL. Projeto de Lei no 4.173/1998. Institui o Plano Nacional de Educação [Apensado ao PL 4.155/1998]. Brasília: Câmara dos Deputados, 12 fev. 1998.

CASTRO, Jorge Abrahão de. Financiamento da educação pública no Brasil: evolução dos gastos. In: OLIVEIRA, Romualdo Portela; SANTANA, Wagner (Org.). Educação e federalismo no Brasil: combater as desigualdades, garantir a diversidade. Brasília: UNESCO, 2010, p. 169-190.

CENTRO DE ESTUDOS EDUCAÇÃO E SOCIEDADE. Educação \& Sociedade, Campinas, v. 31, n. 112, p. 657-676, jul.-set. 2010.

CONFEDERAÇÃO NACIONAL DOS TRABALHADORES EM EDUCAÇÃO. A visão dos(as) trabalhadores(as) em educação sobre o Novo PNE. Cadernos de Educação, Brasília, v. 16, n. 24, jan.-jun. 2011.

FERNANDES, Maria Dilneia; BRITO, Silvia; PERONI, Vera. Sistema e plano nacional de educação: notas sobre conceituação, relação público-privado e financiamento. Revista Brasileira de Estudos Pedagógicos, Brasília, v. 93, p. 565- 578, 2012.

FÓRUM Nacional em Defesa da Escola Pública. Plano Nacional de Educação: proposta da sociedade brasileira. [Consolidado na plenária de encerramento do II CONED, II Congresso Nacional de Educação. Belo Horizonte], nov. 1997.

MÉSZÁROS, István. Para além do Capital. São Paulo: Boitempo Editorial; Campinas: Ed. Unicamp, 2012.

PERONI, Vera Maria Vidal. A democratização da educação em tempos de parcerias entre o público e o privado. Revista de Educação Pública. Cuiabá, v. 19, p. 215 - 227, 2010.

PERONI, Vera Maria Vidal. Mudanças na configuração do Estado e sua influência na política educacional. In: PERONI, Vera Maria Vidal; BAZZO, Vera Lúcia; PEGORARO, Ludimar (Org.). Dilemas da educação brasileira em tempos de globalização neoliberal: entre o público e o privado. Porto Alegre: Ed. UFRGS, 2006.

PERONI, Vera Maria Vidal (Org.). Redefinições das fronteiras entre o público e o privado: implicações para a democratização da educação. Brasília: Liber Livro, 2013.

VIEIRA, Evaldo. A política e as bases do direito educacional. Cadernos CEDES, Campinas, n. 55, p. 9-29, 2001.

WOOD, Ellen Meiksins. Democracia contra o capitalismo a renovação do materialismo histórico. São Paulo: Boitempo Editorial, 2003.

\section{Notas}

1 Integravam o Fndep mais de trinta entidades, dentre elas: Sindicato Nacional dos Docentes das Instituições de Ensino Superior (Andes-SN); Conferência Nacional dos Bispos do Brasil (CNBB); Confederação Nacional dos Trabalhadores em Educação (CNTE); Centro de Estudos Educação e Sociedade (Cedes), Associação Nacional pela Formação dos Profissionais da Educação (Anfope); Associação de Dirigentes das Instituições Federais de Ensino Superior (Andifes); Associação Nacional de Política e Administração da Educação (Anpae); Associação Nacional de Pesquisa e Pós-Graduação em Educação (Anped); Confederação Nacional dos Trabalhadores em Estabelecimentos de Ensino (Contee);
Conselho de Reitores das Universidades Brasileiras (Crub); Central Única dos Trabalhadores (CUT); Federação de Sindicatos de Trabalhadores das Universidades Brasileiras (Fasubra); Movimento dos Trabalhadores Sem-Terra (MST); Sindicato Nacional dos Servidores Federais da Educação Básica e Profissional (Sinasefe); Ordem dos Advogados do Brasil (OAB); União Nacional dos Dirigentes Municipais de Educação (Undime); União Nacional dos Estudantes (UNE), União Brasileira de Estudantes Secundaristas (Ubes), Associação Brasileira de Imprensa (ABI) e Associação Nacional de Educação (Ande).

2 Cabe destacar a importância do Fndep no processo de elaboração do Capítulo III, Seção I, Educação na Constituição Federal de 1988 e também na elaboração da Lei de Diretrizes e Bases de 1996. Sobre esse tema, ver Bollmann (2010).

3 Dentre outros documentos que apresentam análises do PL no 8.035/2010 (BRASIL, 2011), indicamos nas Referências deste artigo os documentos da Conferência Nacional dos Trabalhadores em Educação (2011); da Associação Nacional de Pós-Graduação e Pesquisa em Educação - Anped (2011) e a coletânea temática da Revista Educação e Sociedade 112, Volume 31, jul.-set. (2010).

4 O conteúdo destas emendas pode ser acessado no site do Fórum Nacional De Educação: <http://fne.mec.gov.br/documentos>

5 O Movimento "PNE pra Valer", composto por um coletivo plural de entidades e pessoas, criado e coordenado pela Campanha Nacional pelo Direito à Educação, manteve diálogo constante com a sociedade, divulgando os trâmites do PL no 8.035/2010 (BRASIL, 2011) e dinamizando ações de incidência política por intermédio do site: $<$ www. pnepravaler.org.br>. Durante a tramitação do novo PNE foi criado o Portal "De olho nos Planos", a partir da parceria de instituições vinculadas à área educacional, disponibilizando informações e materiais para uma maior participação social na importante tarefa de acompanhar a tramitação do PL 8035/10, incidir na efetivação do novo PNE, bem como participar na elaboração ou revisão dos planos de educação nos estados e municípios brasileiros. Ver site: <http://www.deolhonosplanos.org.br/>

4 O conteúdo destas emendas pode ser acessado no site do Fórum Nacional De Educação: <http://fne.mec.gov.br/documentos>

5 O Movimento "PNE pra Valer", composto por um coletivo plural de entidades e pessoas, criado e coordenado pela Campanha Nacional pelo Direito à Educação, manteve diálogo constante com a sociedade, divulgando os trâmites do PL no 8.035/2010 (BRASIL, 2011) e dinamizando ações de incidência política por intermédio do site: <www. pnepravaler.org.br>. Durante a tramitação do novo PNE foi criado o Portal "De olho nos Planos", a partir da parceria de instituições vinculadas à área educacional, disponibilizando informações e materiais para uma maior participação social na importante tarefa de acompanhar a tramitação do PL 8035/10, incidir na efetivação do novo PNE, bem como participar na elaboração ou revisão dos planos de educação nos estados e municípios brasileiros. Ver site: $<$ http://www.deolhonosplanos.org.br/>.

6 Trata-se do Recurso contra apreciação conclusiva das Comissões sobre o Projeto de Lei no 8.035, de 2010 que "Aprova o Plano Nacional de Educação para o decênio 2011-2020 e dá outras providências". Disponível em: $<$ http://www.camara.gov.br/proposicoesWeb/fichadetramitacao?idPr oposicao $=553053>$

7 O Fundo de Manutenção e Desenvolvimento do Ensino Fundamental e de Valorização do Magistério (Fundef) vigorou de 1997 a 2006 (cf. BRASIL, 1996b), e o Fundo de Manutenção e Desenvolvimento da Educação Básica e de Valorização dos Profissionais da Educação (Fundeb) tem prazo de vigência entre 2007 e2020 (cf. BRASIL, 2007).

8 Como subsídio para o aprofundamento sobre o tema das várias formas de privatização da educação básica implementadas na atualidade, em todas as suas etapas e modalidades verpublicação indicada nas Referências: PERONI, 2013.

9 A recente aprovação do Programa Nacional de acesso ao Ensino Técnico e Emprego (Pronatec) é um exemplo neste sentido.

${ }^{10}$ As autoras participam de uma pesquisa que está mapeando as formas de materialização do público-privado na educação básica no Brasil e estabelecendo diálogo com grupos de pesquisa sobre o tema na Inglaterra, Argentina e Portugal. Dentre as entidades de caráter privado atualmente envolvidas com a implementação de programas e projetos na área da educação no Brasil, podemos destacar o Movimento Todos pela Educação e algumas fundações que efetivam parcerias público-privado, como o Instituto Ayrton Senna e o Instituto Unibanco.

${ }^{11}$ Sobre a não separação entre o econômico e o político ver Wood (2003).

Artigo recebido em janeiro 2014.

Aprovado em junho 2014. 